\title{
Gebelerde Huzursuz Bacak Sendromunun Uyku Kalitesi ve Kaygı Düzeyi Üzerine Etkisi
}

\author{
Hacer Alan Dikmen $\odot$
}

Selçuk Üniversitesi, Ebelik Bölümü, Konya, Türkiye

Hacer Alan Dikmen, Dr. Öğr. Üyesi

İletişim:

Dr. Öğr. Üyesi Hacer Alan Dikmen Selçuk Üniversitesi, Ebelik Bölümü, Konya, Türkiye

Tel: +905449491300

E-Posta: alanhacer@selcuk.edu.tr

Gönderilme Tarihi : 010 cak 2020

Revizyon Tarihi : 26 Şubat 2020

Kabul Tarihi : 20 Mart 2020
ÖZET

Amaç: Bu çalışmada gebelerde huzursuz bacak sendromunun uyku kalitesi ve kaygı düzeyi üzerine etkisinin incelenmesi amaçlandi.

Çalışma Planı: Tanımlayııı türde yapılan çalışmanın verileri Nisan-Haziran 2019 tarihleri arasında kişisel bilgi formu, Huzursuz Bacak Sendromu (HBS) Tanı Formu, Huzursuz Bacak Sendromu Şiddeti Derecelendirme Skalası (HBSŞDS), Spielberger Sürekli Kaygı Envanteri-STAI Form TX-2 (SSKE) ve Pittsburgh Uyku Kalitesi İndeksi (PUKi) ile 245 gebeden toplandı. İstatistiksel verilerin analizinde tanımlayıcı istatistiklerle birlikte, Student t Testi, Pearson korelasyon analizi, Lojistik ve Linear regresyon analizi kullanıldı.

Bulgular: Gebelerin yaş ortalaması $27,82 \pm 5,70$, gebelik haftası ortalaması $32,55 \pm 5,77$ 'dir. Gebelerin HBS puan ortalaması $6,77 \pm 9,35$, PUKi puan ortalaması $6,54 \pm 4,01$ ve SSKE puan ortalaması $51,08 \pm 10,45$ olarak saptandı. HBS tanı formuna göre gebelerin \% 18 'inde HBS (+) saptandı. HBS varlığı ile PUKi ve HBSŞDS puan ortalaması arasında anlamlı fark saptandı $(p<0,001)$. HBSŞDS ile PUKI puan ortalaması arasında anlamlı, zayıf, pozitif yönlü $(p<0,001)$ ve PUKi ile SSKE puan ortalaması arasında anlamlı, çok zayıf, ilişki vardır $(p=0,003)$. Lojistik regresyon analizine göre gebelerin HBSŞDS puan ortalamasındaki 1 puanlık artış, HBS görülme durumunu 1 puan arttıırken $(p<0,001)$, linear regresyon analize göre gebelerin PUKi puan ortalaması gebelerin HBS şiddetini etkilemektedir $(\mathrm{p}<0,01)$ (Tablo 5).

Sonuç: Çalışmamızda gebelerin HBS ile uyku kaliteleri arasındaki ilişki vardır ancak HBS kaygı düzeylerini etkilememektedir. Doğum öncesi izlemlerde hemşire ve ebeler tüm gebelerin HBS, uyku kalitesi ve kaygı düzeyleri değerlendirmeli ve bilgilendirmelidir.

Anahtar sözcükler: Huzursuz bacak, gebe, hemşire, uyku

\section{THE EFFECT OF RESTLESS LEG SYNDROME IN PREGNANT WOMEN ON SLEEP QUALITY AND ANXIETY LEVEL}

\section{ABSTRACT}

Aim: In this study, it was aimed to examine the effect of restless leg syndrome in pregnant women on sleep quality and anxiety.

Study Design: Data of the descriptive study were collected from 245 pregnant women via a personal information form, Restless Leg Syndrome (RLS) Diagnostic Form, Restless Leg Syndrome Severity Grading Scale (RLSSGS), Spielberger Trait Anxiety InventorySTAI Form TX-2 (SSKE) and Pittsburgh Sleep Quality Index (PSQI), between April-June 2019. In the analysis of the statistical data, descriptive statistics were used besides Student's t-Test, Pearson's correlation analysis, Logistic and Linear regression analysis.

Results: Age and gestational week averages of the pregnant women were $27.82 \pm 5.70$ and $32.55 \pm 5.77$, respectively. The pregnant score averages were found to be; $6.77 \pm 9.35$ for the RLS, $6.54 \pm 4.01$ for the PSQI and $51.08 \pm 10.45$ for the SSKE. According to the RLS Diagnostic Form, RLS (+) was determined in $18 \%$ of the pregnant women. It was determined that there was a significant difference between the RLS presence and the PSQI and RLSSGS score averages $(p<0.001)$. There was a significant, weak and positive correlation between the RLSSGS and PSQI score averages $(p<0.001)$ and a significant and very weak correlation between the PSQI and SSKE score averages $(p=0.003)$. According to the logistic regression analysis, a 1-point increase in the RLSSGS score averages of the pregnant women caused a 1-point increase in the RLS frequency $(p<0.001)$. According to the linear regression analysis, the PSQI score averages of the pregnant women affected their RLS severity $(p<0.01)$ (Table 5$)$.

Conclusion: In our study, there was a correlation between the RLS and sleep quality of pregnant women; however, the RLS did not affect their anxiety levels. Nurses and midwives should evaluate the RLS, sleep quality and anxiety levels of all pregnant women and inform them during prenatal follow-ups.

Keywords: Restless leg, pregnant woman, nurse, sleep 
$\mathbf{H}$ uzursuz bacak sendromu (HBS), Willis-Ekbom hastalığı olarak da bilinen genellikle gece uyurken veya dinlenirken bacaklarda güçlü ve istemsiz hareket ettirme dürtüsü ile kendini gösterir. HBS, uykuya dalmayı engeller ve rahatsızlık hissi ile karakterize bir duyu-motor bozukluğudur (1-3). HBS'nin nedeni henüz tam olarak bilinmese de, hastaların dopaminerjik ve demir tedavisine olumlu yanıt vermesi, dopamin ve demir eksikliğine bağlı olabileceğini düşündürmektedir $(1,3)$. Gebelikte değişen hormonal denge $(1,2,4)$, kandaki folat ve demir miktarının değişimi $(1,5)$, büyüyen uterus, nefes problemleri, reflü gibi fiziksel semptomlara bağlı uyku bozuklukları ve anksiyete HBS semptomlarının başlamasında ve ilerlemesinde önemli bir faktör olarak kabul edilmekte$\operatorname{dir}(1,4,6)$.

Ülkemizde HBS ve gebelerle ilgili sınırlı sayıda çalışma bulunmasına rağmen yapılan epidemiyolojik çalışmalarda gebelerde HBS sıklığı \%19-46 arasında değişmektedir $(3,7,8)$. HBS'nin gebelik üzerindeki en olumsuz etkisi uyku düzenini ve kalitesini bozmasıdır $(2,9)$. Çalışmalar HBS'li gebelerin uyku bozukluğu yaşadığını ve buna bağlı olarak yaşam kalitelerinde düşme olduğunu ortaya koymaktadır $(2,7)$. Gebelikte yaşanan uyku bozuklukları obstetrik komplikasyonlara, erken doğuma, düşük doğum ağırlıklı bebeğe, intrauterin gelişme geriliğine, erken membran rüptürüne, sezaryen oranlarında yükselmeye yol açarken $(10,11)$, annelerin kaygı düzeylerini de yükseltebilmektedir (10,11,12-14).

Gebelikte uyku problemleri ile baş etmek, anne ve fetal sağlığın yükseltilmesi için önemlidir (10). Gebelik fizyolojik bir süreç olmasına rağmen kadınlar için stresli bir deneyimdir (11) ve bu sürece HBS, uyku bozuklukları gibi problemlerin eklenmesi annelerin kaygı düzeyini daha da arttırabilir. Literatürde gebelerin HBS ve uyku kalitesini değerlendiren sınırlı sayıda çalışma olması $(2,7,9)$ ve gebelerin HBS, uyku kalitesi ve kaygı düzeyini bir arada değerlendiren bir çaış̧maya rastlanmaması nedeniyle çalışmamızın hemşirelik ve ebelik literatürüne katkı sağlayacağı düşünülmektedir. Hemşire ve ebelerin gebelerde bakım kalitesini yükseltebilmesi ve HBS, uyku bozuklukları ve yüksek kaygı düzeyleri ile mücadele edebilmeleri için mevcut olan problemi tanımlamaları, aradaki ilişkiyi belirlemeleri ve bu anlamda bakım uygulamalarını planlamaları gerekmektedir. Çalışmamızda gebelerde huzursuz bacak sendromunun uyku kalitesi ve kaygı düzeyi üzerine etkisinin incelenmesi amaçlandı.

\section{Araştırma soruları}

1. Gebelikte huzursuz bacak sendromu uyku kalitesini etkiler mi?
2. Gebelikte huzursuz bacak sendromu kaygı düzeyini etkiler mi?

3. Gebelerde huzursuz bacak sendromu ile uyku kalitesi ve kaygı düzeyi arasında ilişkisi var mıdır?

\section{Gereç ve yöntem}

Araştırmanın türü

Bu çalışma "tanımlayıcı ve ilişki arayıcı" türde yapıldı.

\section{Araştırmanın yapıldığı yer}

Çalışma, bir kadın-doğum ve çocuk hastanesinin gebe polikliniğinde yapıldı. Veriler Nisan-Haziran 2019 tarihleri arasında toplandı. Gebelere çalışma ile ilgili bilgi verilerek, çalışmaya katılmayı kabul eden gebelerden sözlü onamları alındı. Gebeler, veri toplama formlarını 20-30 dakikalık sürede doldurdu. Çalışma verileri hastaneden tahsis edilen özel bir odada mahremiyete dikkat edilerek toplandı. Verilerin toplandığı odanın ılık, aydınlık ve araştırmacı dışında diğer gebe ve sağlık personelinin girişine izin verilmeyecek şekilde olması planlandı.

\section{Araştırmanın değişkenleri}

\section{Bağımsız değişkenler:}

- Gebelerin yaş, öğrenim ve ekonomik durumu gibi sosyo-demografik özellikleri,

- Gebelerin obstetrik özellikleri,

- Gebelerin huzursuz bacak sendromu düzeyi.

\section{Bağımlı değişkenler:}

- Gebelerin uyku kalitesi düzeyi,

- Gebelerin kaygı düzeyi.

\section{Katılımcıların özellikleri}

\section{Çalışmaya alınma ölçütleri:}

- Okur-yazar olan,

- 18-50 yaşları arasında olan,

- 2. ve 3. trimestirde olan,

- Tek fetüs olan,

- Preterm eylem tanısı almayan,

- Illetişim kurulabilenler (mental yetersizliği bulunmamak, görme/işitme engeli bulunmamak).

\section{Çalışma dışı bırakılma ölçütleri:}

- Infertilite tedavisi ile gebe kalmış olan,

- Çoğul gebeliği olan,

- Kronik hastalığı olan, 
- Preeklampsisi - eklampsisi olan,

- Gebeliği tehdit eden hipertansiyon, diyabet, izlem ve tedavi gerektiren akut komplikasyonları olan.

\section{Araştırmanın örneklemi}

Hastanenin gebe polikliniğine başvuran araştırma kriterlerine uyan kadınlar araştırmanın evrenini oluşturdu. Çalışmanın örneklemi Free Statistics Calculators version 4,0 programı ile online A-priori Sample Size Calculator for Multiple Regression hesaplama aracına göre belirlendi (15). Örneklem büyüklüğü, 4 temel değişken ve 35 gözlemlenen değişkene göre, etki büyüklüğü 0,15 (medium), istatistiksel güç 0,90 ve a hata olasılık seviyesi 0,05 olacak şekilde 242 olarak hesaplandı (16). Belirtilen tarihlerde 254 gebe çalışmaya katılmış, veri toplama formalarından 9 tanesi eksik veya hatalı doldurulduğu için 245 veri istatistiksel analizlerde kullanıldı.

\section{Veri toplama araçları}

Veriler; literatür taraması $(1,3,7)$ sonucunda oluşturulan kişisel bilgilerin yer aldığı kişisel bilgi formu, Huzursuz Bacak Sendromu (HBS) Tanı Formu, Huzursuz Bacak Sendromu (HBS) Şiddeti Derecelendirme Skalası, Spielberger Sürekli Kaygı Envanteri-STAI Form TX-2 ve Pittsburgh Uyku Kalitesi İndeksi ile toplandı.

\section{Kişisel bilgi formu}

Kişisel bilgi formu, gebelerin sosyo-demografik ve obstetrik özellikleri (yaş, eşin yaşı, aile tipi, gelir durumu gibi; 21 soru) ile uyku özelliklerini (uyku süresi, gece uyanma gibi; 10 soru) değerlendiren 31 sorudan oluştu.

\section{Huzursuz Bacak Sendromu (HBS) tanı formu}

Tanı formu, Uluslar Arası Huzursuz Bacak Sendromu Çalışma Grubu (International Restless Legs Syndrome Study Group, IRLSSG) tarafından 1995 yılında hasta öyküsüne dayanarak oluşturulmuştur. Formda 5 soru yer almaktadır. Beş tanı kriteri, HBS'nin karakteristik özelliklerine odaklanmıştır. Kriterlerin tümünü karşılayan hastalar HBS tanısı alırlar. Tüm sorulara "evet" yanıtı ile HBS tanısı konulmaktadır (17). Formun Türkçe güvenirlik geçerlik çaIışması Sevim ve ark. (2003) tarafından yapılmış, her maddenin Cronbach alfa katsayısının 0,81'den büyük olduğu bildirilmiştir (18). Bu çalışma için Cronbach alfa katsayısı 0,93 olarak hesaplandı.

Huzursuz Bacak Sendromu (HBS) şiddeti derecelendirme skalası

Klinik uzmanlığa sahip Uluslar Arası Huzursuz Bacak Sendromu Çalışma Grubu (International Restless Legs
Syndrome Study Group, IRLSSG) tarafından geliştirilen skala, 10 sorudan oluşmaktadır (17). İlk üç soru, subjektif HBS şiddeti değerlendirmeyi, 4. ve 5. sorular HBS ile bağlantılı uyku sorunlarını, 6., 7., ve 8. sorular HBS şiddetini ve sıklığını, 9. ve 10. sorular hastaların ruhsal durumunu ve HBS'nin günlük yaşama etkisini değerlendirmeyi sağlar. Her bir sorudaki HBS şiddet değerleri 0-4 puan arasında değişmektedir. Sıfır puan HBS'nin etkisinin olmadığını, 4 puan çok şiddetli etkisinin olduğu şeklinde derecelendirilmektedir (min-max=0-40 puan) (17). Hafif HBS=110, Orta $H B S=11-20$, Şiddetli $H B S=21-30$, Çok Şiddetli HBS=31-40 puan arasında değişir $(17,19)$. Türkiye'de de pek çok çalışmada HBS şiddetini ölçen, güvenle kullanılan bir tanı aracıdır $(3,7)$. Bu çalışma için Cronbach alfa katsayısı 0,97 olarak hesaplandı.

\section{Pittsburgh Uyku Kalitesi Indeksi (PUKi)}

PUKi, Buysse ve ark. (1989) tarafından geliştirilmiş (20) Ağargün ve ark. (1996) tarafından Türkçe geçerlik ve güvenirliği yapılmıştır (21). PUKİ, son bir ay içerisindeki uyku kalitesi ve uyku bozukluğunun tipi ve şiddeti konusunda bilgi sağlar. Toplam 24 sorudan oluşan ölçekte, 18 soru puanlanmaktadır. Ölçek, bireyin "Öznel Uyku Kalitesi", "Uyku Latensi", "Uyku Süresi", "Alışılmış Uyku Etkinliği", "Uyku Bozukluğu", "Uyku Illacı Kullanımı" ve "Gündüz İşlev Bozukluğu" hakkında bilgi veren 7 alt boyuttan oluşmaktadır. Her bir alt boyut 0-3 puan (madde $0=$ hiç sıkıntı ol-

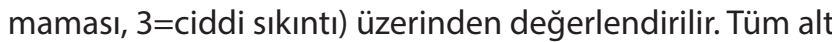
boyutların toplam puanı ölçek toplam puanını verir (minmax=0-21). Toplam puanın 5'ten büyük olması “kötü uyku kalitesini" gösterir. Ölçeğin Türkçe geçerlilik ve güvenilirlik çalışmasında Cronbach alfa güvenirlik katsayısı 0,80 olarak bildirilmiştir (21). Bu çalışma için Cronbach alfa güvenirlik katsayısı 0,84 olarak hesaplandı.

\section{Spielberger durumluluk ve sürekli kaygı envanteri}

Spielberger ve ark. (1970) tarafından geliştirilen, Türkçe geçerlik ve güvenirliği Öner ve Le Compte (1998) tarafından yapılan Durumluluk-Süreklilik Kaygı Envanteri durumluluk için 20, süreklilik için 20 olmak üzere toplam 40 maddeden oluşmaktadır $(22,23)$. Çalışmamızda Süreklilik Kaygı Envanteri kısmı kullanılmış olup, 4'lü Likert tiptedir (1-Hemen hiçbir zaman, 2-Bazen, 3-Çok zaman, 4-Hemen her zaman) $(22,23)$. Ölçekte iki tür ifade bulunmaktadır. Olumsuz duyguları yansıtan ifadeler; "düz ya da doğrudan ifadeler", olumlu duyguları yansıtan ifadeler; "tersine dönmüş" ifadelerdir. Ölçekte 7 tane $(21,26,27,30,33,36$ ve 39 . maddeler) tersine çevrilmiş ifade vardır. Olumlu ifadeler puanlanırken, 1 ağırlık değerinde olanlar 4'e, 4 ağırlık değerindekiler ise 1'e dönüştürülür. Doğrudan ifadeler için elde edilen toplam ağırık puanından, ters ifadelerin toplam ağırlıklı 
puanı çıkartılır. Elde edilen sayıya, Sürekli Kaygı Ölçeği için 35 puan eklenir. En son elde edilen değer bireyin kaygı puanıdır. Ölçekten elde edilen toplam puan değeri 20 ile 80 arasında değişmektedir. Puan yükseldikçe bireyin sürekli kaygı düzeyi de yükselir $(22,23)$. Envanterin Türkçe'ye uyarlama çalışmaları Öner ve Le Compte (1998) tarafından yapılmıştır. Yapılan güvenirlik analizlerinde Cronbach Alfa iç tutarlık katsayısının Sürekli Kaygı ölçeği için 0,83 ile 0,87 arasında olduğu bulunmuştur (23). Bu çalışma için Cronbach alpha güvenirlik katsayısı 0,86 olarak hesaplandı.

\section{Araştırmanın etik yönü}

Araştırma öncesinde etik kurul izni (Tarih; 2019/Karar No; 475) ve araştırmanın yapıldığı hastaneden (Tarih; 08.04.2019/Karar No; 94723667-806.01.03) izin alınmıştır. Araştırmaya katılan tüm gebelere çalışma hakkında bilgi verilerek onamları alındı.

\section{Istatistiksel analiz}

Istatistiksel verilerin analizinde SPSS 20,0 paket programı kullanıldı. Skewnes ve Kurtosis değerleri -1 ve +1 arasında değişen örneklem dağılımımızda parametrik testlerden Student $\mathrm{t}$ Testi ve Pearson korelasyon analizi kullanıldı. İkili analizlerde anlamlı çıkan bağımsız değişkenler Linear ve çok değişkenli regresyon analizi modeline dahil edildi.

\section{Bulgular}

Çalışmamıza katılan gebelerin yaş ortalaması $27,82 \pm 5,70$, gebelik haftası ortalaması $32,55 \pm 5,77$ 'dir. Gebelerin \%51'inde anemi gelişmiş, \%57'si demir kullanmakta ve $\% 45,3$ 'ü düzenli egzersiz yapmaktadır (Tablo 1). Gebelerin gece uyku süresi $7,18 \pm 2,28$ 'di ve $\% 58,4^{\prime}$ ü uykusuzluk problemi yaşadığını belirtti (Tablo 2).

Gebelerin HBS puan ortalaması $6,77 \pm 9,35$, PUKi puan ortalaması $6,54 \pm 4,01$ ve SSKE puan ortalaması $51,08 \pm 10,45$ olarak saptandı. HBS tanı formuna göre gebelerin \%18'inde HBS (+) saptandı. HBS şiddet derecelendirme skalasına göre gebelerin \%20,8'inde "orta" derecede HBS şiddeti saptandı (Tablo 3).

HBS varlığı ile PUKI ve HBSŞDS puan ortalaması arasında anlamlı fark saptandı $(p<0,001)$ (Tablo 4). HBSŞDS ve PUKI puan ortalaması $(r=0,22 ; p<0,001)$ ile PUKI ve SSKE puan ortalaması arasında anlamlı ve pozitif bir ilişki vardır $(r=0,18 ; p=0,003)$. Lojistik regresyon analizine göre gebelerin HBSŞDS puan ortalamasındaki 1 puanlık artış, HBS görülme durumunu 1 puan arttırırken $(p<0,001)$, linear regresyon analize göre gebelerin PUKI puan ortalaması gebelerin HBS şiddetini etkilemektedir $(p<0,01)$ (Tablo 5).
Tablo 1. Gebelerin sosyo-demografik ve obstetrik özelliklerinin dağlımı $(n=245)$

\begin{tabular}{|c|c|}
\hline & $\begin{array}{c}\text { Ortalama } \pm \text { Standart } \\
\text { Sapma }\end{array}$ \\
\hline Yaş & $27,82 \pm 5,70$ \\
\hline Eşin yaşı & $31,23 \pm 6,35$ \\
\hline Evlilik süresi & $6,31 \pm 5,26$ \\
\hline Gebelik haftası & $32,55 \pm 5,77$ \\
\hline Gebelik sayısı & $2,39 \pm 1,55$ \\
\hline \multirow[t]{2}{*}{ Yaşayan çocuk sayısı } & $1,14 \pm 1,13$ \\
\hline & Sayı (yüzde) \\
\hline $\begin{array}{l}\text { Öğrenim durumu } \\
\text { Okur-yazar } \\
\text { Illköğretim } \\
\text { Lise ve üzeri }\end{array}$ & $\begin{array}{l}31(12,7) \\
94(38,4) \\
120(49)\end{array}$ \\
\hline $\begin{array}{l}\text { Eşin öğrenim durumu } \\
\text { Okur-yazar } \\
\text { Illköğretim } \\
\text { Lise ve üzeri }\end{array}$ & $\begin{array}{c}24(9,8) \\
97(39,6) \\
124(50,6)\end{array}$ \\
\hline $\begin{array}{l}\text { Çalışma durumu } \\
\text { Çalışıyor } \\
\text { Çalışmıyor }\end{array}$ & $\begin{array}{c}66(26,9) \\
179(73,1) \\
\end{array}$ \\
\hline $\begin{array}{l}\text { Aile tipi } \\
\text { Çekirdek aile } \\
\text { Geniş aile }\end{array}$ & $\begin{array}{l}191(78) \\
54(22)\end{array}$ \\
\hline $\begin{array}{l}\text { Gelir durumu algısı } \\
\text { İyi } \\
\text { Orta } \\
\text { Kötü }\end{array}$ & $\begin{array}{c}81(33,1) \\
156(63,7) \\
8(3,3)\end{array}$ \\
\hline $\begin{array}{l}\text { En uzun süre yaşanılan yer } \\
\text { Köy/ilçe } \\
\text { il }\end{array}$ & $\begin{array}{c}49(20) \\
196(80)\end{array}$ \\
\hline $\begin{array}{l}\text { Sigara } \\
\text { Evet } \\
\text { Hayır }\end{array}$ & $\begin{array}{c}29(11,8) \\
216(88,2)\end{array}$ \\
\hline $\begin{array}{l}\text { Alkol } \\
\text { Evet } \\
\text { Hayır } \\
\end{array}$ & $\begin{array}{c}3(1,2) \\
242(98,8)\end{array}$ \\
\hline $\begin{array}{l}\text { Abortus/küretaj öyküsü } \\
\text { Evet } \\
\text { Hayır }\end{array}$ & $\begin{array}{c}56(22,9) \\
189(77,1)\end{array}$ \\
\hline $\begin{array}{l}\text { Gebeliği isteme durumu } \\
\text { Evet } \\
\text { Hayır }\end{array}$ & $\begin{array}{c}226(92,2) \\
19(7,8)\end{array}$ \\
\hline $\begin{array}{l}\text { Gebeliğin planlanması } \\
\text { Evet } \\
\text { Hayır }\end{array}$ & $\begin{array}{c}207(84,5) \\
38(15,5)\end{array}$ \\
\hline $\begin{array}{l}\text { Gebelikte herhangi bir sağlık problemi yaşama } \\
\text { Evet } \\
\text { Hayır }\end{array}$ & $\begin{array}{l}125(51) \\
120(49) \\
\end{array}$ \\
\hline $\begin{array}{l}\text { Gebelikte anemi gelişmesi } \\
\text { Evet } \\
\text { Hayır }\end{array}$ & $\begin{array}{l}125(51) \\
120(49)\end{array}$ \\
\hline $\begin{array}{l}\text { Gebelikte demir kullanımı } \\
\text { Evet } \\
\text { Hayır }\end{array}$ & $\begin{array}{l}140(57,1) \\
105(42,9)\end{array}$ \\
\hline $\begin{array}{l}\text { Düzenli egzersiz yapma } \\
\text { Evet (haftada 3-4 kez en az } 30 \text { dakika egzersiz) } \\
\text { Hayır }\end{array}$ & $\begin{array}{l}111(45,3) \\
134(54,7)\end{array}$ \\
\hline
\end{tabular}


Tablo 2. Gebelerin uyku özelliklerinin dağlımı $(n=245)$

\begin{tabular}{lc} 
& $\begin{array}{c}\text { Ortalama } \pm \text { Standart } \\
\text { Sapma }\end{array}$ \\
\hline Uykuya dalmadan yatakta geçirilen süre (dakika) & $35,02 \pm 34,21$ \\
Gece uyku süresi (saat) & $7,18 \pm 2,28$ \\
Gündüz uyku süresi (dakika) & $62,58 \pm 72,71$ \\
\hline & Sayı (yüzde) \\
\hline Uykusuzluk problemi yaşama & \\
Evet & $143(58,4)$ \\
Hayır & $102(41,6)$ \\
\hline Uykuya dalmada güçlük çekme & \\
Evet & $114(46,5)$ \\
Hayır & $131(53,5)$ \\
\hline Uykunun yeterli olması/dinlenmiş uyanma & \\
Evet & $151(61,6)$ \\
Hayır & $94(38,4)$ \\
\hline Uyku sırasında en ufak bir gürültüde bile uyanma & $165(67,3)$ \\
Evet & $80(32,7)$ \\
\hline Hayır & \\
\hline Gece uykunun idrara çıkma isteği ile sık sık & $165(67,3)$ \\
bölünmesi & $80(32,7)$ \\
\hline Evet & \\
Hayır & $184(75,1)$ \\
\hline Gündüz saatlerinde yorgun hissetme & $61(24,9)$ \\
\hline Evet & \\
Hayır & $192(78,4)$ \\
\hline Gün içerisinde yorgun hissetme & $74(30,2)$ \\
Evet & $77(31,4)$ \\
\hline Hayır & $94(38,4)$ \\
\hline Çay, kahve, kola gibi kafeinli içeceklerden günlük & \\
bir su bardağından fazla tüketme & \\
Hayet & \\
Bazen & \\
\hline
\end{tabular}

Tablo 3. Gebelerin huzursuz bacak sendromu (HBS), uyku ve kaygı özelliklerinin dağılımı $(n=245)$

\begin{tabular}{lccc} 
& Ortalama \pm Standart Sapma & Minimum & Maksimum \\
\hline HBS & $6,77 \pm 9,35$ & 0 & 38 \\
PUKi & $6,54 \pm 4,01$ & 0 & 18 \\
SSKE & $51,08 \pm 10,45$ & 27 & 80 \\
\hline \multicolumn{1}{c}{ HBS Tanı Formuna Göre HBS } & Sayı & $\%$ \\
\hline & Varlığı & 44 & 18 \\
HBS (+) & 201 & 82 \\
HBS (-) & Sayı & $\%$ \\
\hline & HBS Şiddet Derecelendirme & 142 & 58 \\
Skalasına Göre HBS Dereceleri & HBS yok (0) & 25 & 10,2 \\
& Hafif (1-10) & 51 & 20,8 \\
Orta (11-20) & 24 & 9,8 \\
& Şiddetli (21-30) & 3 & 1,2 \\
\hline
\end{tabular}

HBS, huzursuz bacak sendromu; PUKi, Pittsburgh uyku kalitesi indeksi; SSKE, Spielberger sürekli kaygı envanteri.
Tablo 4. HBS varlığı ile Pittsburgh Uyku Kalitesi Indeksi (PUKI), Spielberger Sürekli Kaygı Envanteri (SSKE) ve Huzursuz Bacak Sendromu Şiddeti Derecelendirme Skalası (HBSŞDS) puan ortalamalarının karşıllaştırıması $(n=245)$

\begin{tabular}{lccc} 
& $\begin{array}{c}\text { PUKi } \\
\text { Ortalama } \pm \\
\text { Standart Sapma }\end{array}$ & $\begin{array}{c}\text { SSKE } \\
\text { Ortalama } \pm \\
\text { Standart Sapma }\end{array}$ & $\begin{array}{c}\text { HBSŞDS } \\
\text { Ortalama } \pm \\
\text { Standart Sapma }\end{array}$ \\
\hline $\begin{array}{l}\text { HBS (+) } \\
(\mathrm{n}=44)\end{array}$ & $8,25 \pm 4,21$ & $53,86 \pm 11,11$ & $19,93 \pm 7,35$ \\
$\begin{array}{l}\text { HBS (-) } \\
(\mathrm{n}=201)\end{array}$ & $6,17 \pm 3,88$ & $50,49 \pm 10,24$ & $3,89 \pm 6,94$ \\
Anlamlllkk Testi* & t: 3,175 & t: 1,931 & t: 13,730 \\
\hline P: 0,002 & p: 0,055 & p: 0,000 \\
\hline $\begin{array}{l}\text { P<, } 05 \\
\text { *Student t Testi }\end{array}$ & & & \\
\hline
\end{tabular}

Tablo 5. Huzursuz Bacak Sendromu Şiddeti Derecelendirme Skalası (HBSŞDS), Pittsburgh Uyku Kalitesi Indeksi (PUKI) ve Spielberger Sürekli Kaygı Envanteri (SSKE) arasındaki ilişki $(n=245)$

\begin{tabular}{lccc} 
& & PUKi & SSKE \\
\hline \multirow{2}{*}{ HBSŞDS* $^{*}$} & $r$ & 0,223 & 0,093 \\
\multirow{2}{*}{ PUKi } & $p$ & 0,000 & 0,149 \\
& $\mathrm{r}$ & - & 0,187 \\
& $\mathrm{p}$ & - & 0,003 \\
\hline
\end{tabular}

*Pearson Korelasyon analizi.

Tablo 6. Huzursuz Bacak Sendromu ve Huzursuz Bacak Sendromu şiddeti ile uyku kalitesi arasındaki lojistik ve linear regresyon analizi

\begin{tabular}{|c|c|c|c|c|}
\hline $\operatorname{HBS}(+)^{*}$ & p & $\begin{array}{l}\text { Odds ratio } \\
\text { (OR) }\end{array}$ & $\begin{array}{c}\text { \%95 CI } \\
\text { Düşük değer }\end{array}$ & Yüksek değer \\
\hline PUKI & 0,355 & 1,242 & 0,943 & 1,179 \\
\hline \multirow[t]{2}{*}{ HBSŞDS } & 0,000 & 1,054 & 1,169 & 1,319 \\
\hline & & & & $\begin{array}{c}\mathbf{t} \\
3,552\end{array}$ \\
\hline HBSŞDS **Belirleyici & B & SD & Beta & $p$ \\
\hline PUKI & 0,096 & 0,027 & 0,223 & 0,000 \\
\hline
\end{tabular}

\section{Tartışma}

Gebelik, HBS semptomlarının başlamasında ve alevlenmesinde bir risk faktörü olarak kabul edilmiş olup, HBS'nin ise uyku bozukluklarına neden olduğu gösterilmiştir. Bu durumun intrauterin gelişme geriliği, preeklampsi gibi gebelikte istenmeyen etkilerle ilişkili olduğu bildirilmiştir (3). Ayrıca gebelikteki uyku sorunları depresyon ve kaygı gibi psikolojik problemlere de yol açabilmektedir (10-11). Çalışmamızda gebelerde huzursuz bacak sendromunun uyku kalitesi ve kaygı düzeyi üzerine etkininin incelenmesi amaçlanmıştır. 
Çalışmamızda HBS tanı formuna göre gebelerin $\% 18$ 'inde, HBS şiddetini derecelendirme skalasına göre \%42'sinde HBS varlığı bulundu. HBS şiddeti derecelendirme skalasına göre gebelerin beşte birinde HBS şiddeti orta düzeydeydi. Literatürde HBS varlığı gebelerde \%19-46 olarak bildirilmiştir $(3,7,8)$. Çalışma bulgularımız literatür ile paralellik göstermektedir.

Çalışmamızda gebeler kötü uyku kalitesine sahipti (PUKi puan ortalaması $=6,54 \pm 4,01)$. Köybaşı ve Oskay (2017) çalışmasında gebelerin \%72'sinin kötü uyku kalitesine sahip olduğunu belirtirken (24), benzer çalışmalarda gebelik döneminde uyku kalitesinin bozulduğunu bildirmektedir $(6,25,26)$. Çalışma bulgumuz literatür bulguları ile benzer olup, gebelik uyku kalitesi üzerinde önemli bir faktördür ve gebelikte uyku problemleri yaygın bir sorundur. Gebelikte uyku problemlerinin diabetes mellitus, pelvik inflamatuvar hastalığı, preeklampsi riskinde artış, preterm doğum, düşük doğum ağırlığı, intrauterin gelişme geriliği, düşük apgar skoru ve yenidoğanın yoğun bakım ünitesi intiyacı gibi anne ve fetal sağlığı ilgilendiren pek çok kötü perinatal sonuçları olduğu bildirilmiştir $(6,27,28)$. Bu nedenle kadın sağlığı hemşireleri ve ebeler doğum öncesi bakım hizmetleri kapsamında gebelerin uyku kalitelerini mutlaka değerlendirilmelidir. Hemşireler ve ebeler uyku kalitesinin bozuk olduğunu saptadıkları gebelerde uyku problemlerinin nedenlerini sorgulamalı ve nedene yönelik gerekli bakım hizmetlerini sunmalıdır.

Çalışmamızda HBS'nin uyku kalitesini etkilediği saptandı. Literatürde gebelerde HBS varlığının uyku bozukluklarını arttırdığı bildirilmiştir $(2,3,9,29)$. Çalışma sonuçlarımız literatür ile paralellik göstermektedir. Gebelik döneminde HBS varlığı kötü uyku kalitesi için bir risk faktörü olabilmektedir. Hemşire ve ebeler gebelerde HBS varlığını doğum öncesi izlemlerde sorgulamalı, HBS (+) olan gebelerde uyku kalitesi değerlendirilmelidir. Hemşireler HBS semptomlarını düşünerek gebelerin uyku bozukluğu, yorgunluk, kaygı ve stres nedenlerini tartışmasına izin vermeli ve birlikte çözüm yolları aranmalıdır (34). Gebelere HBS ile nasıl başa çıkacakları ya da semptomların nasıl hafifletileceğinin de öğretilmesi gerekmektedir. Bireylere gündüz uykusundan kaçınması, HBS semptomlarını tetiklediği düşünülen kafein, alkol, tütün gibi uyaranlardan uzak durması ve yatağa sadece uyumak için gitmesi gerektiği hemşireler tarafından öğretilmelidir (30).
Çalışmamızda gebelerin kaygısı orta düzeydeydi (SSKE puan ortalaması $=51,08 \pm 10,45)$. Gebelik döneminde kadınların gerek fiziksel, sosyal ve psikolojik değişimlere bağlı, gerekse doğum korkusu ve bebeği ile ilgili endişeleri nedeni ile kaygı ve stres düzeyleri yükselebilmektedir (11-14,31,32). Hemşireler ve ebeler gebelerin kaygı düzeylerini mutlaka değerlendirmeli ve kaygı düzeylerini azaltacak müdahaleleri yapmalıdır.

Gebelerde HBS varlığı ve şiddeti ile kaygı düzeyi arasında anlamlı bir fark saptanmazken, PUKI ile SSKE puan ortalaması arasında anlamlı ve pozitif bir ilişki vardı $(p=0,003)$. Ertekin Pınar ve ark. (2014) gebelerde uyku kalitesinin kötüleştikçe algılanan stres düzeyinin artıı̆ını saptarken (11), benzer çalışmalarda da gebelerde kötü uyku kalitesi ile depresif ve anksiyete semptomları (14), emosyonel distres (15), negatif duygu durumu (28), stres ve kaygı (12) arasında ilişki olduğu bildirmektedir. Çalışma bulgularımızı literatür desteklemektedir. Uyku kalitesinin kötü olması gebelerde gün içerisinde gerginlik yaratarak kaygı düzeylerini arttırabilir (33). Gebelerin yaşadıkları uyku ve kaygı ile ilgili sorunları azaltarak anne ve bebek sağlığını geliştirmek öncelikle hemşire ve ebelerin sorumluluğudur. Bu nedenle gebelerin doğum öncesi dönemde yaşadıkları uyku sorunları ve kaygı düzeyleri değerlendirmelidir (11).

\section{Sinırlılıklar}

Çalışma bulguları örneklem grubu ile sınırlıdır, topluma genellenemez. Veriler öz bildirime dayandığı için gebelerde HBS varlığı, uyku kalitesi ve kaygı düzeyleri subjektif verilerdir.

\section{Sonuçlar ve öneriler}

Çalışmamızda gebelerin yaklaşık beşte birinde HBS pozitiftir ve şiddeti orta düzeydedir. Gebelerin HBS ile uyku kaliteleri arasındaki ilişki vardır ancak HBS kaygı düzeylerini etkilememektedir. Doğum öncesi izlemlerde hemşire ve ebeler gebeleri HBS, kötü uyku kalitesi ve kaygı düzeyi açısından değerlendirmeli, bu problemlerle baş etmeleri konusunda bilgilendirmeli, doğum öncesi izlemlere düzenli gelmeleri sağlanmalıdır. Gebelerde HBS varlığının saptanması ve sunulacak bakım hizmetlerinin planlanması için daha genişörneklem grubu ile çalışmalar yapılmalıdır. 


\section{Kaynaklar}

1. Bilgilisoy Filiz M, Çakır T. Güncel tanı kriterleri ile huzursuz bacak sendromu. Turk J Osteoporos 2015;21:87-95. [CrossRef]

2. Liu G, Li L, Zhang J, Xue R, Zhao X, Zhu K, et al. Restless legs syndrome and pregnancy or delivery complications in China: a representative survey. Sleep Med 2016;17:158-62. [CrossRef]

3. Yüksel B, Seven A, Yıldız YK, Kucur S, Gözükara I, Polat $M$, et al. Gebelikte huzursuz bacak sendromu. JGON 2015;12:144-6.

4. Sarberg $M$, Josefsson $A$, Wiréhn AB, Svanborg $E$. Restless legs syndrome during and after pregnancy and its relation to snoring. Acta Obstet Gynecol Scand 2012;91:850-5. [CrossRef]

5. Patrick L. Restless legs syndrome: pathophysiology and the role of iron and folate. Altern Med Rev 2007;12:101-12. http://archive. foundationalmedicinereview.com/publications/12/2/101.pdf

6. Çelik F, Köse M. Gebelikte uyku kalitesinin trimester ile ilişkisi. Kocatepe Tıp Derg 2017;18:85-8. [CrossRef]

7. Akbaş $P$. Gebelerde huzursuz bacak sendromu sıklığı ve yaşam kalitesi üzerine etkisinin değerlendirilmesi, Gazi Üniversitesi, Sağlık Bilimleri Enstitüsü, Hemşirelik Anabilim Dalı Yüksek Lisans Tezi, Ankara, 2017. s.37-59.

8. Tunç T, Karadağ YS, Doğulu F, İnan LE. Predisposing factors of restless legs syndrome in pregnancy. Mov Disord 2007;22:627-31. [CrossRef]

9. Sönmez A. Huzursuz bacak sendromu olan gebelere verilen uyku hijyeni eğitiminin uyku kalitesine etkisi. İnönü Üniversitesi Sağlık Bilimleri Enstitüsü, Ebelik Anabilim Dalı Yüksek Lisans Tezi, Malatya, 2017. s.23-33.

10. Chang JJ, Pien GW, Duntley SP, Macones, GA. Sleep deprivation during pregnancy and maternal and fetal outcomes: is there a relationship? Sleep Med Rev 2010;14:107-14. [CrossRef]

11. Ertekin Pınar Ş, Arslan Ş, Polat K, Çiftçi D, Cesur B, Dağlar G. Gebelerde uyku kalitesi ile algılanan stres arasındaki ilişkinin incelenmesi. DEUYHOEDERGI 2014;7:171-7. http://www.deuhyoedergi.org/ index.php/DEUHYOED/article/view/95/346

12. Palagini L, Gemignani A, Banti S, Manconi M, Mauri M, Riemann D. Chronic sleep loss during pregnancy as a determinant of stress: impact on pregnancy outcome. Sleep Med 2014;15:853-9. [CrossRef]

13. Polo-Kantola P, Aukia L, Karlsson H, Paavonen E. Sleep quality during pregnancy: associations with depressive and anxiety symptoms. Acta Obstet Gynecol Scand 2017;96:198-206. [CrossRef]

14. Volkovich E, Tikotzky L, Manber R. Objective and subjective sleep during pregnancy: links with depressive and anxiety symptoms. Arch Womens Ment Health 2016;19:173-81. [CrossRef]

15. Soper DS. A-priori sample size calculator for multiple regression [Software]. http://www.danielsoper.com/statcalc

16. Cohen J, Cohen P, West SG, Aiken LS. Applied Multiple Regression/ Correlation Analysis for the Behavioral Sciences, 3rd ed. Mahwah, NJ: Lawrence Earlbaum Associates; 2014.
17. Walters AS, LeBrocq C, Dhar A, Hening W, Rosen R, Allen RP, et al. Validation of the International Restless legs Syndrome Study Group rating scale for restless legs syndrome. Sleep Med 2003;4:121-32. [CrossRef]

18. Sevim S, Dogu O, Camdeviren H, Bugdayci R, Sasmaz T, Kaleagasi H, et al. Unexpectedly low prevalence and unusual characteristics of RLS in Mersin, Turkey. Neurology 2003;61:1562-9. [CrossRef]

19. Hening WA, Allen RP. Restless legs syndrome (RLS): the continuing development of diagnostic standards and severity measures. Sleep Med 2003;4:95-7. [CrossRef]

20. Buysse DJ, Reynolds CF 3rd, Monk TH, Berman SR, Kupfer DJ. The Pittsburgh Sleep Qualityal. Index: a new instrument for psychiatric practice and research. Psychiatry Res 1989;28:193-213. [CrossRef]

21. Ağargün MY, Kara $H$, Anlar Ö. Pittsburgh uyku kalitesi indeksinin geçerliği ve güvenirliği. Turk Psikiyatri Derg 1996;7:107-15.

22. Sevinç S, Özdemir S. Hemşirelik öğrencilerinin kaygı ve umutsuzluk ilişkisi: Kilis örneği. HEMAR-G 2017;19:14-24. http://hemarge.org.tr/ ckfinder/userfiles/files/2017/vol19sayi2/(2).pdf

23. Öner N, Le Compte A. Durumluk-sürekli kaygı envanteri el kitabı. İstanbul: Boğaziçi Üniversitesi Yayını, 1998.

24. Köybaşı EŞ, Oskay ÜY. Gebelik sürecinin uyku kalitesine etkisi. Gülhane Tıp Derg 2017;59:1-5.

25. Mindell JA, Cook RA, Nikolovski J. Sleep patterns and sleep disturbances across pregnancy. Sleep Med 2015;16:483-8. [CrossRef]

26. Yang Y, Mao J, Ye Z, Li J, Zhao H, Liu Y, Li J. Determinants of sleep quality among pregnant women in China: a cross-sectional survey. $J$ Matern Fetal Med 2018;31:2980-5. [CrossRef]

27. Antony KM, Agrawal A, Arndt ME, Murphy AM, Alapat PM, Guntupalli KK, Aagaard KM. Association of adverse perinatal outcomes with screening measures of obstructive sleep apnea. J Perinatol 2014;34:441-8. [CrossRef]

28. Ding XX, Wu YL, Xu SJ, Zhang SF, Jia XM, Zhu RP, et al. A systematic review and quantitative assessment of sleep-disordered breathing during pregnancy and perinatal outcomes. Sleep Breath 2014;18:703-13. [CrossRef]

29. Chen PH, Liou KC, Chen CP, Cheng SJ. Risk factors and prevalence rate of restless legs syndrome among pregnant women in Taiwan. Sleep Med 2012;13:1153-7. [CrossRef]

30. Hensley JG. Leg cramps and restless legs syndrome during pregnancy. J Midwifery and Womens Health 2009;54:211-8. [CrossRef]

31. Schuurmans C, Kurrasch DM. Neurodevelopmental consequences of maternal distress: what do we really know? Clin Genet 2013;83:10817. [CrossRef]

32. Yali M, Lobel M. Stress-resistance resources and coping in pregnancy. Anxiety Stress Coping 2009;15:289-309. [CrossRef]

33. Alvaro PK, Roberts RM, Harris JK. A systematic review assessing bidirectionality between sleep disturbances, anxiety, and depression. Sleep 2013;36:1059-68. [CrossRef] 